|| ISSN(online): 2589-8698 || ISSN(print): 2589-868X || International Journal of Medical and Biomedical Studies

Available Online at www.ijmbs.info

PubMed (National Library of Medicine ID: 101738825)

Index Copernicus Value 2018: 75.71

Original Research Article

Volume 3, Issue 10; October: 2019; Page No. 287-290

IJMBS

\title{
ROLE OF ORAL ANTIBIOTICS IN ELECTIVE COLORECTAL SURGERY
}

\section{Dr. Amit Ramesh Churi}

Assistant Professor Dept. of General Surgery Vedanta Institute of Medical Sciences Dahanu, Palghar, Maharashtra

Article Info: Received 08 October 2019; Accepted 27 October 2019

DOI: https://doi.org/10.32553/ijmbs.v3i10.694

Corresponding author: Dr. Amit Ramesh Churi

Conflict of interest: No conflict of interest.

\section{Abstract:}

Introduction: Surgical site infection (SSI) is a major burden for patients who are posted for elective colorectal surgery, also there is significant increase to the cost of health care.it is a major cause of morbidity after surgery and is associated with increased hospital stay, readmissions, costs, and sometimes mortality. Surgical site infections are very high in colorectal surgery and are estimated to vary from 15\% to 30\% of patients undergoing colorectal surgery. For colorectal surgeries, orally administered antibiotics can be used in addition to the intravenous antibiotic prophylaxis.

Material and Methods: A total of 46 patients were included in the study who were posted for elective colorectal surgery. Patients who start with the 3-day intervention period but for whom surgery is cancelled or postponed for more than 7 days, will not be evaluable for analysis. After enrolment, patients were randomly assigned to one of two treatment arms in a 1:1 ratio. Patients were blinded into two groups, group 1 (medication group) and group 2 (placebo group). Patients are instructed to take the medication four times daily, during the last 3 days prior to surgery.

Results: There were 16 (69.6\%) male and 7 (30.4\%) in medication group while in placebo group male were 15 (65.2\%) and female were 8 (34.8\%). Mean age in medication group was $46.2 \pm 15.24$ and in placebo group was $48.2 \pm 14.55$. BMI (Body mass index) in medication group was $29.44 \pm 3.74$ and in placebo group was $28.76 \pm 2.96$. Operative time in group medication was $6.4 \pm 2.12$ and in placebo group was $6.23 \pm 1.96$. This was not significant. Surgical site infection (SSI) in medication group was $3(13 \%)$ and in placebo group was $8(39 \%)$. Mean Hospital stay (days) in medication group was $13.11 \pm$ 2.45 and in placebo group was $16.2 \pm 3.87$, this was statistically significant. No. of antibiotics required postoperatively in medication group was $.2 \pm 1.4$ and in placebo group was $6.4 \pm 2.4$.

Conclusion: Administration of oral antibiotics 3 days prior to colorectal surgery can significantly reduce the surgical site infection and mean hospital stay thereby reducing the morbidity.

Keywords: antibiotics, colorectal surgery, SSI, MBP and BMI

\section{Introduction}

Surgical site infection (SSI) is a major burden for patients who are posted for elective colorectal surgery, also there is significant increase to the cost of health care.it is a major cause of morbidity after surgery and is associated with increased hospital stay, readmissions, costs, and so metimes mortality ${ }^{i}$, ii.

Administration of preoperative bowel preparation has been shown to reduce the incidence of SSI in the hospitals. The role of mechanical bowel preparation (MBP) with polyethylene glycol or sodium phosphate has been studied in randomized controlled trials (RCTs), with perceived benefits including ease of manipulation of the bowel, reduced spillage and resultant contamination, reduced luminal pressure, and reduce bacterial load ${ }^{\mathrm{iii}}$. Surgical site infections are very high in colorectal surgery and are estimated to vary from $15 \%$ to $30 \%$ of patients undergoing colorectal surgery ${ }^{\text {iv }}$.

Even after taking extensive efforts for improving infection control practice, the incidence of SSIs after colorectal surgery remains unaffectedly high, whereas in other surgical specialties the incidence appears to have declined ${ }^{\mathrm{v}}$.

It is important to understand the pathogenesis of SSIs to establish infection prevention measures,. There is microbial contamination of the surgical site and development of the infection ${ }^{\mathrm{vi}}$. One of the important measure to check the risk of postoperative infections is to intravenously administer perioperative prophylactic antibiotics $^{\text {vii }}$. For colorectal surgeries, orally administered antibiotics can be used in addition to the intravenous antibiotic prophylaxis. This contains non-absorbable antibiotics, like neomycin which is combined with erythromycin or 
metronidazole, that are administered 1 to 2 days prior to the surgical procedure. The non-absorbable nature of these antibiotics implies almost complete absence of systemic uptake after oral intake. These antibiotics, have low risks of side effects also exert local activity in the gastrointestinal tract and also reduce the colonic bacterial contamination levels directly at the surgical site, whereas systemic antibiotics are can be used as a safeguard by establishing effective antibiotic concentrations in the soft tissues to minimize the risk of infection. But because of large variability in the antibiotic regimen it is very difficult to choose the correct antibiotics ${ }^{\text {viii }}$.

\section{Material and Methods}

Present study was carried out in the Department of Surgery at Vedanta Institute of Medical Sciences and Hospital.

Patient included were adult patients undergoing elective colorectal surgery. Patients were excluded if age is less than 18 years, Patients with a documented allergy to colistin or aminoglycoside antibiotics, Patients diagnosed with myasthenia gravis, Patients with a pre-existent stoma, Patients who have an inability to take medication orally and patients who refused to participate in the present study. Written informed consent was obtained from all the participants.

A total of 46 patients were included in the study who were posted for elective colorectal surgery. Patients who start with the 3-day intervention period but for whom surgery is cancelled or postponed for more than 7 days, will not be evaluable for analysis. After enrolment, patients were randomly assigned to one of two treatment arms in a 1:1 ratio. Patients were blinded into two groups, group 1 (medication group) and group 2 (placebo group). Patients are instructed to take the medication four times daily, during the last 3 days prior to surgery.

Primary endpoint was measured as deep SSI and/or mortality within 30 days of surgery. Superficial and deep SSIs was diagnosed according to the CDC criteria for surgical site infectionsix. Blood culture were taken for any bacterial infection and identification. Patients were followed up until 6 months after surgery to evaluate the development of primary and secondary outcomes.

The difference in the primary outcome between Pre$\mathrm{OP}$ and placebo will be estimated with a Z-test for proportions or by logistic regression, correcting for the stratification variable (study site). Multivariable logistic regression will be used and measured confounders will be fitted in the model as covariates. Secondary outcomes will be analyzed using the chisquare test, Fisher's exact test, logistic regression, time-to-event analysis, $t$ test or Mann-Whitney $U$ test, when appropriate.

\section{Observations and Results}

A total of 46 patients were included in the study and were divided in 2 groups: group 1 (medication group) and group 2 (placebo group) of 23 each.

Table 1: Demographic va riable

\begin{tabular}{llll}
\hline Variable & Group 1 (medication group) & Group 2 (placebo group) & P value \\
\hline Age (mean \pm SD) & $46.2 \pm 15.24$ & $48.2 \pm 14.55$ & NS \\
\hline Male & $16(69.6 \%)$ & $15(65.2 \%)$ & NS \\
\hline Female & $7(30.4 \%)$ & $8(34.8 \%)$ & NS \\
\hline BMl & $29.44 \pm 3.74$ & $28.76 \pm 2.96$ & NS \\
\hline
\end{tabular}

NS: Not significant, BMI: Body mass index.

Demographic variables in both the groups were not significant. There were $16(69.6 \%)$ male and $7(30.4 \%)$ in medication group while in placebo group male were15 (65.2\%) and female were 8 (34.8\%). Mean age in medication gro up was $46.2 \pm 15.24$ and in placebo group was $48.2 \pm 14.55$. BMI (Body mass index) in medication group was $29.44 \pm 3.74$ and in placebo group was $28.76 \pm 2.96$.

Table 2: Comparison of groups

\begin{tabular}{llll}
\hline Characteristics & Group 1 (medication group) & Group 2 (placebo group) & P value \\
\hline Postoperative time (hours) & $6.4 \pm 2.12$ & $6.23 \pm 1.96$ & $\mathrm{P}=0.7790, \mathrm{NS}$ \\
\hline SSI (n, \%) & $3(13 \%)$ & $8(39 \%)$ & $\mathrm{P}=0.0468$ \\
\hline MeanHospital stay (days) & $13.11 \pm 2.45$ & $16.2 \pm 3.87$ & $\mathrm{P}=0.0023$ \\
\hline No. of postoperative antibiotics required & $4.2 \pm 1.4$ & $6.4 \pm 2.4$ & $\mathrm{P}=0.0004$ \\
\hline
\end{tabular}

SSI: Surgical site infection 
Operative time in group medication was $6.4 \pm 2.12$ and in placebo group was $6.23 \pm 1.96$. This was not significant. Surgical site infection (SSI) inmedication group was $3(13 \%)$ and in placebo group was $8(39 \%)$. Mean Hospital stay (days)in medication group was $13.11 \pm 2.45$ and in placebo gro up was $16.2 \pm 3.87$, this was statistically significant. No. of antibiotics required postoperatively in medication group was $.2 \pm 1.4$ and in placebo group was $6.4 \pm 2.4$.

\section{Discussion}

Complications such as SSI after colorectal surgeries are associated with significant morbidity, therefore, there is an important need to reduce preventable complications and improve quality of care. In our study there was a significant reduction in SSI inmedication group was $3(13 \%)$ and in placebo group was $8(39 \%)$ in patients who received antibiotics preoperatively. Similar results were observed by Ohman et al in their studyfound that patients who received both oral antibiotics and mechanical bowel preparation had a significantly lower rate of SSI compared with no preparation at all ${ }^{\mathrm{x}}$. Roos $\mathrm{D}^{\mathrm{xi}}$ in their study observed that a suspension of colistin sulphate, tobramycin and amphotericin B was used to reduce anastomotic leakage and postoperative infectious complications. In our study we have omitted the antifungal drug as fungi are rarely identified as the causative pathogens of SSIs after surgical procedures on the lower gastrointestinal tract ${ }^{\mathrm{xii}}$.

In our study it was observed that Mean Hospital stay (days) in medication group was $13.11 \pm 2.45$ and in placebo group was $16.2 \pm 3.87$, this was statistically significant. No. of antibiotics required postoperatively in medication group was $.2 \pm 1.4$ and in placebo group was $6.4 \pm 2.4$.these values were statistically significant. We administered antibiotics 3 days prior to surgery, thus prophylaxis in our study is restricted to the preoperative period. In a study by et al it was observed that the treatment period of 3 days will be sufficient since the decontamination will least for several days. Continuation of the prophylaxis in the postoperative period is not necessary as there is a risk of developing antibiotic resistance or opportunistic infections postoperatively $y^{x i i}$.

\section{Conclusion}

Administration of oral antibiotics 3 days prior to colorectal surgery can significantly reduce the surgical site infection and mean hospital stay thereby reducing the morbidity.

\section{References}

1. Shepard J, Ward W, Milstone A, et al. Financial impact of surgical site infections on hospitals: the hospital management perspective. JAMA Surg 2013;148: 907e 914.

2. Mahmoud NN, Turpin RS, Yang G, Saunders WB. Impact of surgical site infections on length of stay and costs in selected colorectal procedures. Surg Infect (Larchmt) 2009;10: 539e544

3. Rollins KE, Javanmard-Emamghissi $H$, Lobo DN. Impact of mechanical bowel preparation in elective colorectal surgery: a meta-analysis. World I Gastroenterol 2018; 24:519-536.

4. Keenan JE, Speicher PJ, Thacker JK, et al. The preventive surgical site infection bundle in colorectal surgery: an effective approach to surgical site infection reduction and health care cost savings. JAMA Surg 2014;149:1045e1052.

5. European Centre for Disease Prevention and Control. Surveillance of surgical site infections in Europe 20102011. Stock ECDC; 2013.

6. Mangram AJ, Horan TC, Pearson ML, Silver LC, Jarvis WR.Guideline for prevention of surgical site infection, 1999. Hospital Infection Control Practices Advisory Committee.Infect Control HospEpidemiol. 1999 Apr; 20(4):250-78; quiz 279-80.

7. Baum ML, Anish DS, Chalmers TC, Sacks HS, Smith H Jr, Fagerstrom RM. A survey of clinical trials of antibiotic prophylaxis in colon surgery: evidence against further use of no-treatment controls.N Engl J Med. 1981 Oct 1; 305(14):795-9.

8. Nelson RL, Gladman E, Barbateskovic M Antimicrobial prophylaxis for colorectal surgery.Cochrane Database Syst Rev. 2014 May 9; (5):CD001181.

9. Horan TC, Gaynes RP, Martone WJ, Jarvis WR, Emori TG. CDC definitions of nosocomial surgical site infections, 1992: a modification of CDC definitions of surgical wound infections. Infect Control Hosp Epidemiol. 1992;20:271-4.

10. Ohman KA, Wan L, Guthrie T, Johnston B, Leinicke JA, Glasgow SC, Hunt SR, MutchMG. Wise PE, Silviera ML. Combination of Oral Antibiotics and Mechanical Bowel Preparation Reduces Surgical Site Infection in Colorectal Surgery.J Am Coll Surg. 2017 Oct;225(4): 465-471. doi: 10.1016/j.jamcollsurg.2017.06.011. Epub 2017 Jul 6.

11. ${ }^{x i}$ Roos D, Dijksman LM, Oudemans-van Straaten HM, de Wit LT, Gouma DJ, Gerhards MF. Randomized clinical trial of perioperative selective decontamination of the digestive tract versus placebo in elective gastrointestinal surgery. Br J Surg. 2011 Oct; 98(10):1365-72.

12. Referentiecijfers module Postoperatieve wond infecties. http://www.rivm.nl/Onderwerpen/P/PREZIE 
S/Incidentieonderzoek_POWI/Referentiecijfers_POWI/ Referentiecijfers_POWI_2012_2016.org

13. Mulder T, Kluytmans-van den Bergh MFQ, de Smet AMGA, et al. Prevention of severe infectious complications after colorectal surgery using preoperative orally administered antibiotic prophylaxis (PreCaution): study protocol for a randomized controlled trial. Trials. 2018;19(1):51. Published 2018 Jan 19. doi:10.1186/s13063-018-2439-4 